\title{
"Relaparoscopic" management of surgical complications: The experience of an Emergency Center
}

\author{
Antonino Agrusa ${ }^{1} \cdot$ Giuseppe Frazzetta $^{3,4} \cdot$ Daniela Chianetta $^{1} \cdot$ Silvia Di Giovanni $^{2}$ • \\ Leonardo Gulotta ${ }^{1}$ - Giuseppe Di Buno ${ }^{1}$ - Vincenzo Sorce ${ }^{1}$ - Giorgio Romano ${ }^{1}$. \\ Gaspare Gulotta ${ }^{1}$
}

Received: 22 May 2015/Accepted: 4 September 2015/Published online: 21 October 2015

(C) Springer Science+Business Media New York 2015

\begin{abstract}
Background/aim Laparotomy has been the approach of choice for re-operations in patients with surgical complications. The aim of this retrospective analysis was to evaluate the feasibility and the safety of laparoscopic approach for the management of general abdominal surgery complications.

Materials and methods We report a retrospective review of 75 patients who underwent laparoscopic evaluation for postoperative complications over a 4-year period. Primary outcomes (resolution rate by exclusive laparoscopic approach, conversion rate, further surgery rate) and secondary outcomes (mortality, hospitalization, prolonged ileus, wounds problems and median operative time) were evaluated.

Results Sixty-six patients (88\%) were managed with laparoscopic approach without conversion; of these, sixtythree patients (84\%) had no more or further complications and were discharged from hospital between $4 \pm 3$ days after "second-look" surgery; three patients (4\%) developed postoperative complications requiring a third surgery.
\end{abstract}

Giuseppe Frazzetta

giuseppe.frazzetta@libero.it

1 Dipartimento di Chirurgia Generale e d'Urgenza, Policlinico Universitario "Paolo Giaccone", Palermo 90121, Sicily, Italy

2 Ospedale "Umberto I" ", U.O. Medicina e Chirurgia d'Accettazione e d'Urgenza, ASP n ${ }^{\circ}$, Contrada Ferrante, Enna 94100, Sicily, Italy

3 Ospedale "Michele Chiello", Unità Operativa Complessa di Chirurgia Generale e d'Urgenza, ASP n ${ }^{\circ}$ Contrada Bellia, 94015 Piazza Armerina, Sicily, Italy

4 Ospedale "Umberto I ${ }^{\circ}$ ", Unità Operativa Complessa di Chirurgia Generale e d'Urgenza, ASP n ${ }^{\circ} 4$, Contrada Ferrante, 94100 Enna, Sicily, Italy
Nine cases $(12 \%)$ underwent conversion in open surgery after laparoscopic approach. Two elderly patients $(2.7 \%)$ died in intensive care unit, because of multi-organ failure syndrome. Median time elapsed between an intervention and another was about $2.5 \pm 9.5$ days. Mean operative time was $90 \pm 150 \mathrm{~min}$. Postoperative hospital stay was between 4.5 and 18 days.

Discussion and conclusion Laparoscopy has begun to be the preferred method to manage postoperative problems, but only few reports are available actually. Our experience in "relaparoscopic" management of surgical complications seems to suggest that laparoscopy "second look" is an effective tool after open or laparoscopic surgery for the management of postoperative complications and it may avoid diagnostic delay and further laparotomy and related problems.

Keywords Relaproscopy - "Second-look" surgery • Surgical complications . "Redo" surgery

Since first laparoscopic cholecystectomy, in 1987 by Mouret [1], laparoscopic surgery has become the treatment of choice of many pathologies and a useful diagnostic tool [2-4]. Furthermore, laparoscopy begins to be used in emergency setting, such as septic shock, peritonitis and bleeding, with excellent results [5-8]. Planned second-look laparoscopy is used to verify bowel viability in mesenteric ischemia treatment $[9,10]$. Despite the relevant advantages, minimally invasive surgery has its risks and complications with an incidence variable between 0.05 and $8 \%$ [11]. Some postoperative findings are common after open or laparoscopic surgery, such as free gas in the abdomen, remaining free fluid, blood or minimal bile leakage, and are often misinterpreted as normal characteristics. Few studies 
demonstrated the useful of laparoscopic approach to detecting postoperative complications after open or laparoscopic surgery [12]. Misinterpretation could lead to diagnostic delay of postoperative complications, instead a timely identification, and management of adverse events may result in better outcome for the patient [13]. Laparotomy for a long time has been the approach of choice for re-operations in patients with previous laparoscopic or open surgery. Abdominal re-exploration by laparotomy is associated with higher incidence of peritoneal infection, pain, prolonged ileus, wound septic complications and delayed discharge. Until now, only few reports are available in published papers about outcomes of laparoscopic treatment of postoperative complications after open or laparoscopic surgery. According to current trends, gradually laparoscopy has begun to be the preferred method to manage patients with suspected postoperative complications [14]. In this paper, we report our experience about revision, re-exploration and solution of complications of surgical procedures previously performed both in open and in laparoscopic way. Few are the report in literature and the most limited about only a kind of procedures.

\section{Materials and methods}

We perform a retrospective design on a small cohort study of 75 selected patients, whom underwent laparoscopic evaluation for postoperative complications, with the aim to evaluate the feasibility and the safety of full laparoscopic resolution as second approach for the management of general abdominal surgery complications. No control group of open surgery is actually available. We considered a period between January 2010 and January 2014 considering both elective surgery and emergency setting. Data were collected from operative reports of the Department of General and Emergency Surgery of Policlinico of Palermo. Demographic and clinical presentation data including age, sex, American Society of Anesthesiologist Score, time elapsed between first surgeries and "second look" are

Table 1 Patient's Data

\begin{tabular}{ll}
\hline Patient's characteristics & Data \\
\hline Mean age (years) & $56(18-87)$ \\
Gender F/M & $43 / 32$ \\
Median elapsed time "first to second" & $2.5 \pm 9.5$ days \\
ASA score & \\
I & 2 \\
II & 3 \\
III & 39 \\
IV & 31 \\
\hline
\end{tabular}

resumed in Table 1; 43 patients were female and 32 male; mean age was 56 years (range 18-87). ASA (American Society of Anesthesiologists) score was: ASA I for 2 patients, ASA II for 3 patients and ASA III for 31 patients, and for 39 patients, ASA score was IV. The patient population included postoperative complications in patients still hospitalized after the first surgery and patients readmitted within $8 \pm 2$ days. Median elapsed time between first and second approach was $2.5 \pm 7.5$ days. The readmissions over 10 days for the reasonable suspicion of intense adhesions formation were excluded; we preferred to manage these patients by open approach.

Fifty-two patients had previous emergency surgery for acute/perforated cholecystitis, acute appendicitis, diverticulitis, hemoperitoneum, gastric and bowel perforation or mechanical bowel obstruction; 23 patients of this study were previously treated with elective surgery for colon-rectal cancer, gallstone disease, chronic recurrent appendicitis, splenic abscess or spherocytosis. Primary procedures were: open surgery in 20 patients; percutaneous in 3 patients; endoscopic in 3 patients; and laparoscopic surgery in 49 patients (Table 2). As soon as it has been revealed the occurrence of postoperative complications, it was decided to run surveys for the definition of the type and severity of the complication itself. The need for a second surgery was made based on clinical evaluation and evidence of instrumental data. Candidates for the second surgery were all those situations in which the strategy of "wait and see" could not be applied for more than $48 \mathrm{~h}$ in the absence of obvious signs of improvement; so rapid anemia, bleeding, gastric-bowel tear, bile leak, obstructions, intense pain and peritonitis, etc., were postoperative complications to treat surgically.

Indication to "second-look surgery" was: first of all, clinical presentations and physical assessment, both vital signs and laboratory marks trend, the presence of fever, then the presence of free fluid or organized biliary or blood collections; the presence of bile or blood or intestinal fluid in the drainage, excessive postoperative pain; gastric tears and bowel tears; suspected bile leak; septic shock; prolonged ileus; suspected anastomotic leakage; clinical sign of acute abdomen; refractory fever; clinical sign of intestinal occlusion (Table 3). We decide to include, in this evaluation, percutaneous and endoscopic complications too, because these previous procedures were, however, also strongly invasive and were performed by surgeons of the same department whom themselves tried to solve their complications by surgery. The criteria that lead to a decision to use laparoscopic technique are here resumed. All these cases considered in the study, which we decide to approach by laparoscopic "second look," were selected among a bigger number of postoperative complications based on some criteria. First of all, the decision of a laparoscopic re-exploration was conditioned by the 
Table 2 Previous Invasive Procedures

\begin{tabular}{|c|c|c|c|c|c|c|c|}
\hline Previous procedures & Open & Laparoscopic & Endoscopic & Percutaneous & Urgency & Elective & Total \\
\hline Cholecystectomy & 5 & 15 & & & 16 & 4 & 20 \\
\hline Splenectomy & 1 & 3 & & & 1 & 3 & 4 \\
\hline Appendectomy & 2 & 10 & & & 7 & 5 & 12 \\
\hline Anterior rectal resection (R.A.R) & 2 & 2 & & & 1 & 3 & 4 \\
\hline Surgery for hemoperitoneum & 4 & 5 & & & 9 & 0 & 9 \\
\hline Gastric sutures & 2 & 4 & & & 6 & 0 & 6 \\
\hline Colon resection & 4 & 4 & & & 5 & 3 & 8 \\
\hline Bowel obstruction & 4 & 0 & & & 4 & 0 & 4 \\
\hline Abscesses drainage & & 2 & & 2 & 3 & 1 & 4 \\
\hline Biliary stenting & & & 3 & 1 & 0 & 4 & 4 \\
\hline Total & 20 & 49 & 3 & 3 & 52 & 23 & 75 \\
\hline
\end{tabular}

Table 3 Criteria to a "redo" surgery

\begin{tabular}{lc}
\hline Indications for surgical re-operation & Number of patients \\
\hline Intense postoperative pain & 15 \\
Fever refractory to therapy & 11 \\
Anemia & 7 \\
Septic shock & 2 \\
Prolonged paralytic ileus & 3 \\
Bowel obstruction & 3 \\
Suspected biliary leak/jaundice & 7 \\
Suspected anastomotic leak & 5 \\
Peritonitis/acute abdomen & 21 \\
Abdominal compartment syndrome (ACS) & 1 \\
Total & 75 \\
\hline
\end{tabular}

availability and of an experienced laparoscopic team with advanced laparoscopic skills; general clinical condition was one of the most important decisive criterion: All patients should be hemodynamically stable with no perfusion problems or lung or heart failure. Local wound conditions were decisive to drive the decisions about the choice of the tipe of surgical access: Only patients with good healing wounds were approached by laparoscopy and were selected for the study. Open access was preferred when wounds were infected or not in good local conditions. Presence of previous umbilical or median pre-intraperitoneal mesh was a strong indication to laparoscopic approach. All patients with suspected complications and candidate to a second-look surgery were subjected to an accurate clinical and physical evaluation, blood tests and laboratory examinations. All of them underwent ultrasound study using convex 5-3 and linear 7-9 $\mathrm{MHz}$ probes to scan all abdomen and thorax in each one [15]. Thirty-five patients were subjected to direct abdomen X-ray, searching for occlusion and obstruction signs, sub-diaphragmatic free gas, or other indirect signs of intra-abdominal fluid collections, while in 29 patients, an additional computed tomography scan was necessary before re-operation to clarify complexity of the case when echographic or X-ray examinations were not clear. In 12 sufferers, a preoperative endoscopic retrograde cholangiopancreatography (ERCP) was performed for endoscopic diagnosis, and in some cases, treatment of bile leaks or bile ducts injuries even afterward surgery was necessary to assure bile collections drainage or peritoneal cleaning [16]. In five cases, methylene blue administration was necessary, and in four patients, gastrografin was used to study intestinal viability and integrity (Table 4).

\section{Technique}

Only expert surgeon with advanced laparoscopic technique skills carried out all the surgical procedures; the same surgical team led all re-interventions. Patient position was chosen in agreement with previous surgical procedures and preoperative radiological suggested data. The classical French position was preferred for those who underwent previously upper GI surgery or the American classic position for patient with lower GI surgery; Trendelenburg or anti-Trendelenburg position and right or left rotation

Table 4 Preoperative tests

\begin{tabular}{lr}
\hline Preoperative instrumental examinations & 75 \\
Ecography/FAST & 29 \\
Computed tomography scan & 35 \\
Abdomen X-ray & 5 \\
DPL (diagnostic peritoneal lavage) & 2 \\
ERCP (endoscopic retrograde cholangiopancreatography) & 5 \\
Methylene blue administration & 4 \\
Gastrografin administration & 4 \\
\hline
\end{tabular}


were applied in order to obtain a complete exploration of all abdominal cavity recesses. In all cases of previous laparoscopic surgery, pneumoperitoneum was achieved through a 12-mm umbilical trocar inserted by open transumbilical Hasson technique, rarely blindly, and maintained to $12 \mathrm{mmHg}$. In patients with previous open surgery, Veress needle was used to insufflate abdominal cavity, placed in Palmer's point, away from previous laparotomic wound. Access to abdominal cavity was obtained, in most cases, through the previous ports sites. In all cases were used a $10 \mathrm{~mm} 30^{\circ}$ scope and other 5-10 mm trocars were placed under direct vision. Previous port sites were preferred to access abdominal cavity; when necessary new ports were set in order to better management of the suspected abdominal complications. All the procedures began with a careful and complete peritoneal cavity exploration. Intra-operative findings were various: peritoneal abscesses, active bleeding, persisting free intra-abdominal fluid, bile collection due to bile leak or duodenal/retroperitoneal perforation, pancreatic collection due to pancreatic fistula, gastric or colic perforation and anastomotic leakage with peritonitis, and in some cases, significant pathologic findings were not found (Table 5). The "second-look" laparoscopic procedures performed were: drainage of abscesses and/or hematoma and/or fluid collection, peritoneal lavage and toilette, bowel suture or/and resection, bile leak repair, colic resection or/and colostomy, gastric suture or/and resection and adhesiolysis (Table 6). Previous surgery sites were examined, and atraumatic instruments were used for gentle separation of omental adhesions and bowel evaluation. All the abdominal recesses were explored in over- and sub-mesocolic lodges; in some cases, aspiration of bile, blood, pus or enteric/gastric content were performed. Intra-operative ERCP was performed in all

Table 5 Intraoperative findings

\begin{tabular}{lc}
\hline Intra-operative findings & Patients \\
\hline Intra-abdominal abscesses & 15 \\
Hematoma/bleeding & 7 \\
Free intra-abdominal fluid & 13 \\
Bile leak & 2 \\
Duodenal/retroperitoneal perforations & 1 \\
Pancreatic fistula & 3 \\
Intestinal tear & 7 \\
Gastric tear & 5 \\
Bowel necrosis & 3 \\
Adhesions with ileus & 10 \\
Anastomotic leakage & 3 \\
Colic tear & 4 \\
Without pathological findings & 2 \\
Total & 75 \\
\hline
\end{tabular}

cases of bile leak or biliary injury suspicion (Fig. 1). If necessary, methylene blue was administered to individuate none directly visualized gastric-bowel injury. All surgical procedures were concluded through wide irrigation by physiological solution to clean all peritoneal cavity, and one, two or three drainage tubes were ever placed. All cases, in which no evident causes of complications were detected, underwent laparotomy.

\section{Results}

Seventy-five patients underwent laparoscopic evaluation for suspected postoperative complications of previous open or laparoscopic surgery. Our primary outcome measure was to evaluate the feasibility and the resolution rate of a totally laparoscopic approach, the conversion rate and the further surgery rate; secondary outcomes were: mortality rate, median operative time, median hospitalization, development of prolonged ileus ( $>96 \mathrm{~h}$ ), development of wound problems (dehiscence, needing of VAC therapy, infections, etc.), and they are resumed in Table 7.

Median time elapsed between an intervention and another was about $8.5 \pm 72.3 \mathrm{~h}$. Mean operative time was $90 \pm 150 \mathrm{~min}$. Nine cases (12\%), in which complications could not be solved by laparoscopic approach, underwent conversion in open surgery; in this group one patient died because of wound complications, sepsis and respiratory distress. Causes of conversion were: severe intestinal adhesion, absence of significant findings, difficult or altered anatomy, uncontrollable bleeding, misidentification of source of leakage. Remaining 66 patients (88\%) were managed with full laparoscopic approach without conversion in open surgery. Of these, sixty-three patients (84\%) had no more or further complications and had a regular postoperative course and were discharged from hospital between $4.5 \pm 3$ days after exclusive laparoscopic secondlook surgery. Three patients (4\%), among those who had received a second totally laparoscopic approach, developed postoperative complications such as persisting free abdominal fluid, extraordinary abdominal pain, sore and tense abdomen: They required a further open surgical procedures (as third surgery); in this group, one patient was transferred to intensive care unit, because of evolving multi-organ failure syndrome, where he died. Overall mortality after "redo" surgery was of $2.7 \%$ : Two elderly patients ( 82 years old) with ASA score IV related to respiratory and cardiac complications, and both had previous emergency open surgery for acute peritonitis due to gastric or colonic perforations. Postoperative hospital stay was $4.5 \pm 18$ days with rapid discharge (4.5-6.5 days) for whom who required only peritoneal drainage of bile, blood and purulent collections. Hospital stay was longer (5.2-9.5) 
Table 6 Laparoscopic "Second look"

\begin{tabular}{lcl}
\hline "Second-look" laparoscopic procedures & Total laparoscopic & Conversion to open \\
\hline Drainage of abscesses or hematoma or fluid collections & 32 & 0 \\
Gastric suture & 4 & 0 \\
Bowel resection & 2 & 1 \\
Colic resection/colostomy & 5 & 2 \\
Bowel suture & 6 & 1 \\
Bile leak repair & 1 & 1 \\
Gastric resection & 0 & 1 \\
Adhesiolysis & 5 & 1 \\
Abdominal lavage & 11 & 0 \\
Without pathological findings & 0 & 2 \\
Total = 75 & 66 & 9
\end{tabular}
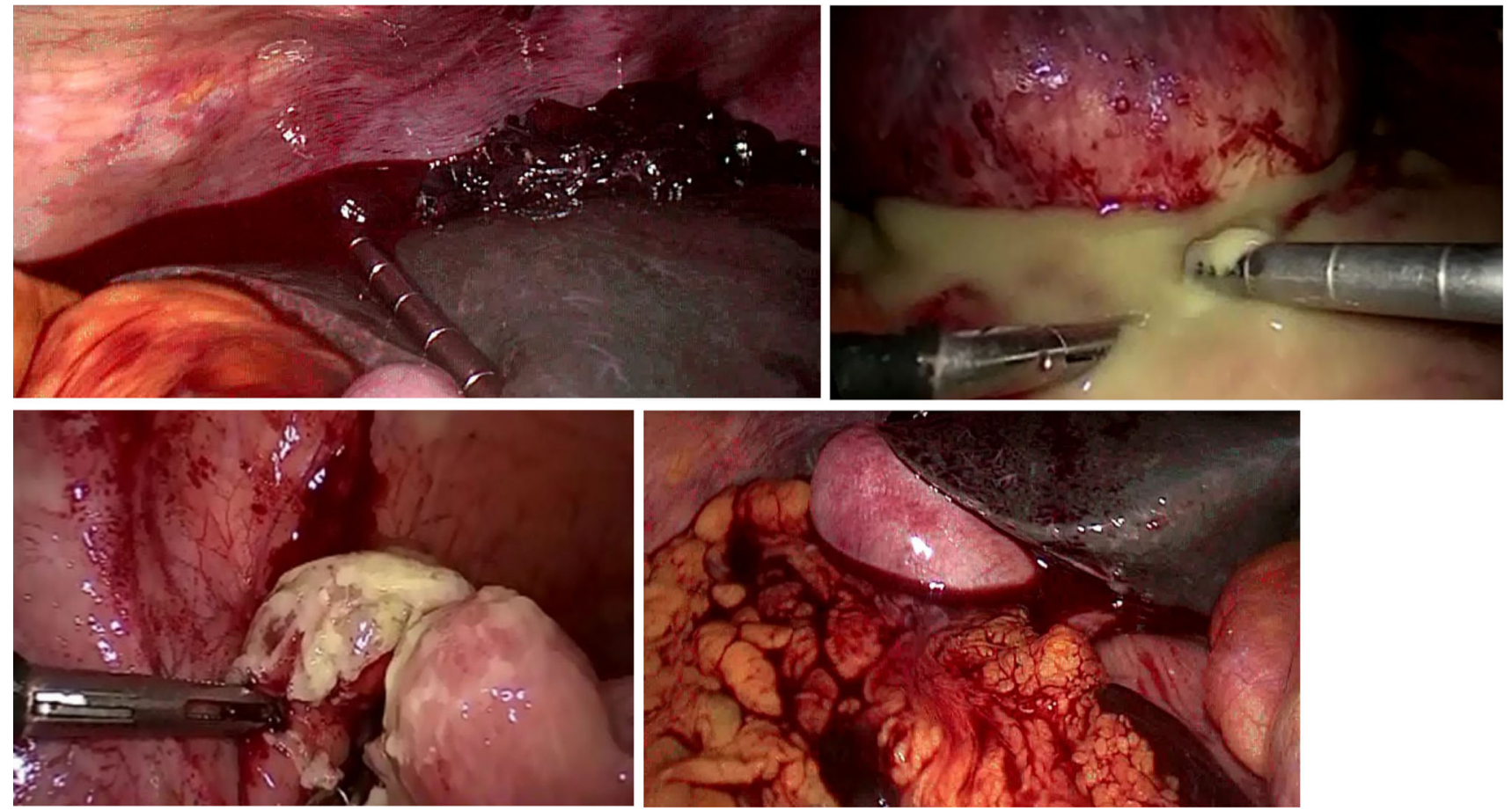

Fig. 1 Intraoperative findings and "second look" procedures

for all the patients whom necessitated conversion to open surgery and/or a third operation (7.5-18 days); in these patients, longer immobilization, more lasting postoperative ileus, higher postoperative pain and rate of postoperative wound infections were found (Table 7).

\section{Discussion and conclusion}

Surgical complications, even the unexpected ones, are common events both in open and in laparoscopic approach. Some of them can resolve spontaneously, but some other could persist in time, requiring a "second-look" surgery to stop potentially dramatic chain of adverse events. After open or laparoscopic surgery, some postoperative findings could be normal, such as a small free remaining fluid, lower blood loss, small share of free gas, or prolonged postoperative fever. However, surgeon may pay attention to all these findings, and give them the correct interpretation, because often they could be underestimated and evolve in time. Misinterpretation of postoperative complications could lead to difficult situations to resolve and stop; a "second-look" surgery should be considered as soon as a postoperative complication is suspected and its trend is not toward spontaneous resolution. Laparoscopic management of postoperative complications is an open question for 
Table 7 Outcomes

\begin{tabular}{|c|c|c|c|c|c|c|}
\hline & & \multicolumn{5}{|c|}{ Secondary outcomes } \\
\hline & & Mortality & $\begin{array}{l}\text { Prolonged ileus } \\
(>96 \mathrm{~h})\end{array}$ & Wound problems & $\begin{array}{l}\text { Hospitalization } \\
\text { (days) }\end{array}$ & $\begin{array}{l}\text { Median operative } \\
\text { time (min) }\end{array}$ \\
\hline \multicolumn{7}{|l|}{ Primary outcomes } \\
\hline Total laparoscopic solution & $\begin{array}{c}63 / 75 \text { cases } \\
(84 \%)\end{array}$ & $\begin{array}{l}0 / 63 \text { cases } \\
(0 \%)\end{array}$ & $\begin{array}{r}5 / 63 \text { cases } \\
(7.93 \%)\end{array}$ & $\begin{array}{l}8 / 63 \text { cases } \\
(12.69 \%)\end{array}$ & $4.5-6.5$ & $90 \pm 20$ \\
\hline Conversion & $\begin{array}{l}9 / 75 \text { cases } \\
(12 \%)\end{array}$ & $\begin{array}{l}\text { 1/9 case } \\
\quad(11.11 \%)\end{array}$ & $\begin{array}{l}6 / 9 \text { cases } \\
(66.66 \%)\end{array}$ & $\begin{array}{l}\text { 5/9 cases } \\
\quad(55.55 \%)\end{array}$ & $5.2-9.5$ & $120 \pm 30$ \\
\hline Third surgery & $\begin{array}{c}3 / 75 \text { cases } \\
(4.5 \%)\end{array}$ & $\begin{array}{l}1 / 3 \text { case } \\
(33.33 \%)\end{array}$ & $\begin{array}{l}2 / 3 \text { cases } \\
(66.66 \%)\end{array}$ & $\begin{array}{l}3 / 3 \text { cases } \\
(100 \%)\end{array}$ & $7.5-18$ & $180 \pm 60$ \\
\hline Total & 75 & $\begin{array}{l}2 / 75 \text { cases } \\
(2.7 \%)\end{array}$ & $\begin{array}{r}13 / 75 \text { cases } \\
(17.33 \%)\end{array}$ & $\begin{array}{r}16 / 75 \text { cases } \\
(21.33 \%)\end{array}$ & Median 8.5 & Median $90 \pm 150$ \\
\hline
\end{tabular}

general and emergency surgeon [17]. The presence of a recent scar makes it reasonable to re-access through the same abdominal wound. However, abdominal re-exploration by laparotomic access may increase morbidity such as postoperative abdominal pain, wounds infections, sepsis, abnormal wound healing and increased rate of incisional hernia, prolonged ileus, respiratory failure and prolonged bed rest and hospital stay [18]. Relaparoscopic approach is simple, and if negative do not increase morbidity, it could reduce an additional surgical trauma and could avoid further complications in patients suffered of postoperative complications needing a redo surgery; when done early, the old port is still open and accessible, and pneumoperitoneum can be achieved bluntly [19, 20]. A recent laparotomy could not be a contraindication to a mini-invasive laparoscopic management of general surgery postoperative complications. Laparoscopy allows a complete and magnified visualization of the entire abdominal cavity with more attention to details. We support the idea that a minimally invasive "second-look" laparoscopic surgery could be a useful tool in treatment of postoperative laparoscopic or open complications, avoiding a "retrauma" and mortification on the same places and on the same tissues. This could lead to a reduction in short and long-term morbidity, a shorter hospital stay, reduction in wound infections or dehiscence and healing problems. In this study, even if a control group is not available, on 75 patients with surgical complications, 63 patients, corresponding to $84 \%$, were handled laparoscopically; this rate is high and corresponds to enhanced patient's and surgeons satisfaction. These patients had all the benefit of laparoscopy as minor overall trauma, less pain, less respiratory distress, shorter postoperative ileus, early mobilization and food intake, shorter hospitalization, shorter bed rest and early return to daily activities than patients who needed conversion in open surgery $(12 \%)$ or a third surgery $(4 \%)$. Literature review: Our results seem to be in agreement with those of the literature even if few reports are available regarding the management of surgical complications by laparoscopic approach. Kirshtein et al. [21] report a retrospective study on sixty-four patients with postoperative complications managed by laparoscopic approach; in his review, the rate of conversion was $14.1 \%$ and related morbidity $12.5 \%$. Sefr et al. performed laparoscopy, diathermy to the site of bile leakage and drain in three patients, with resolution in days; Brooks et al. solved the problem by laparoscopic drainage in two patients after 7 days and one needed ERCP [22, 23]. Willis et al. [24] report their experience on laparoscopic management of postoperative bile leakage on $15 / 1779$ patients, with a satisfying solution rate and they assure that in selected patients laparoscopy is useful in management of minor bile leak. Leister and Becker [25] reported in 2006 the benefit of laparoscopic approach I in the field of visceral surgery stating that relaparoscopy could be an alternative to laparotomy for laparoscopic complications. Interesting report on urological filed by Vitagliano et al. [26] about the management of abdominal postoperative complications following urological procedures with a complete solution by laparoscopic approach. Our experience allows us to state that relaparoscopy for the management of general abdominal postoperative surgical complications is safe and feasible in experienced hand and could avoid further trauma and worst postoperative outcomes.

\section{Compliance with ethical standards}

Disclosures Antonino Agrusa, Giuseppe Frazzetta, Daniela Chianetta, Silvia Di Giovanni, Vincenzo Sorce, Di Buono Giuseppe, Leonardo Gulotta, Giorgio Romano and Gaspare Gulotta have no conflict of interest or financial ties to disclose.

\section{References}

1. Blum CA, Adams DB (2011) Who did the first laparoscopic cholecystectomy? J Minim Access Surg. 7(3):165-168 
2. Agrusa A, Romano G, Frazzetta G, Chianetta D, Sorce V, Di Buono G, Gulotta G (2014) Role and outcomes of laparoscopic cholecystectomy in the elderly. Int J Surg. 12(Suppl 2):S37-S39

3. Saeian K, Reddy KR (1999) Diagnostic laparoscopy: an update. Endoscopy. 31(1):103-109

4. Agrusa A, Romano G, Frazzetta G, Chianetta D, Sorce V, Di Buono G, Gulotta G (2014) Laparoscopic adrenalectomy for large adrenal masses: single team experience. Int $\mathrm{J}$ Surg. 12(Suppl 1):S72-S74. doi:10.1016/j.ijsu.2014.05.050

5. Sauerland S, Agresta F, Bergamaschi R, Borzellino G, Budzynski A, Champault G, Fingerhut A, Isla A, Johansson M, Lundorff P, Navez B, Saad S, Neugebauer EA (2006) Laparoscopy for abdominal emergencies: evidence-based guidelines of the European Association for Endoscopic Surgery. Surg Endosc 20(1): 14-29

6. Navez B, Navez J (2014) Laparoscopy in the acute abdomen. Best Pract Res Clin Gastroenterol 28(1):3-17

7. Di Saverio S (2014) Emergency laparoscopy: a new emerging discipline for treating abdominal emergencies attempting to minimize costs and invasiveness and maximize outcomes and patients' comfort. J Trauma Acute Care Surg. 77(2):33

8. Agrusa A, Romano G, De Vita G, Frazzetta G, Chianetta D, Di Buono G, Gulotta G (2014) Adrenal gunshot wound: laparoscopic approach. Report of a case. Int J Surg Case Rep 5(2):70-72

9. Slutzki S, Halpern Z, Negri M, Kais H, Halevy A (1996) The laparoscopic second look for ischemic bowel disease. Surg Endosc 10(7):729-731

10. McGinty JJ Jr, Hogle N, Fowler DL (2003) Laparoscopic evaluation of intestinal ischemia using fluorescein and ultraviolet light in a porcine model. Surg Endosc 17(7):1140-1143

11. Kirshtein B, Roy-Shapira A, Domchik S, Mizrahi S, Lantsberg L (2008) Early relaparoscopy for management of suspected postoperative complications. J Gastrointest Surg. 12(7):1257-1262

12. Alaswad FD. (2013) Treatment options of laparoscopic complications. NMC Speciality Hospital ABDOMINAL SURGERY Official Journal of the American Society of Abdominal Surgeons, Inc. Winter 2012/Spring 2013 issue of the Journal

13. Dexter SP, Miller GV, Davides D, Martin IG, Sue Ling HM, Sagar PM, Larvin M, McMahon MJ (2000) Relaparoscopy for the detection and treatment of complications of laparoscopic cholecystectomy. Am J Surg 179(4):316-319

14. Cuccurullo D, Pirozzi F, Sciuto A, Bracale U, La Barbera C, Galante F, Corcione F (2015) Relaparoscopy for management of postoperative complications following colorectal surgery: ten years experience in a single center. Surg Endosc 29(7): 1795-1803. doi:10.1007/s00464-014-3862-6
15. Agrusa A, Romano G, Frazzetta G, Amato G, Chianetta D, Di Giovanni S, De Vita G, Di Buono G,Sorce V, Gulotta G (2014) The aid of "bedside ultrasonography" for the emergency surgeon: the experience of a single centre. Crit Ultrasound J 6(Suppl 2):A3

16. Romano G, Agrusa A, Frazzetta G, De Vita G, Chianetta D, Di Buono G, Amato G, Gulotta G (2013) Laparoscopic drainage of liver abscess: case report and literature review. G Chir 34(5-6): 180-182

17. Rosin D, Zmora O, Khaikin M, Bar Zakai B, Ayalon A, Shabtai M (2004) Laparoscopic management of surgical complications after a recent laparotomy. Surg Endosc 18(6):994-996

18. Lee CM, Huh JW, Yun SH, Kim HC, Lee WY, Park YA, Cho YB, Chun HK (2015) Laparoscopic versus open reintervention for anastomotic leakage following minimally invasive colorectal surgery. Surg Endosc 29(4):931-936. doi:10.1007/s00464-0143755-8

19. Wind J, Koopman AG, van Berge Henegouwen MI, Slors JF, Gouma DJ, Bemelman WA (2007) Laparoscopic reintervention for anastomotic leakage after primary laparoscopic colorectal surgery. Br J Surg 94(12):1562-1566

20. O'Riordan JM, Larkin JO, Mehigan BJ, McCormick PH (2013) Re-laparoscopy in the diagnosis and treatment of postoperative complications following laparoscopic colorectal surgery. Surgeon. 11(4):183-186

21. Kirshtein B, Roy-Shapira A, Domchik S, Mizrahi S, Lantsberg L (2008) Early relaparoscopy for management of suspected postoperative complications. J Gastrointest Surg. 12(7):1257-1262

22. Serf R, Ochmann J, Kozumplik L, Vrastyak J, Penka I (1995) The role of relaparoscopy in the management of bile leaks after laparoscopic cholecystectomy. Int Surg 80:356-357

23. Brooks DC, Becker JM, Connors PJ, Carr-Loke DL (1993) Management of bile leaks after laparoscopic cholecystectomy. Surg Endos 7:292-295

24. Willis VL, Jorgensen JO, Hunt DR (2000) Role of relaparoscopy in the management of minor bile leakage after laparoscopic cholecystectomy. Brit J Surg 87:176-180

25. Leister I, Becker H (2006) Relaparoscopy as an alternative to laparotomy for laparoscopic complication. Chirug 77(11):986-997

26. Vitagliano G, Castilla R, Fernandez Long JG (2013) Relaparoscopy in the treatment of complications after laparoscopic urological procedures. Arch Esp Urol 66(2):215-220 